\title{
SEMANGAT PROFESIONALISME DALAM PERIBAHASA MINANGKABAU
}

\author{
Oktavianus \\ Fakultas Ilmu Budaya Universitas Andalas Padang \\ Korespondensi: Kampus Limau Manis Padang, Sumatera Barat \\ Pos-el : okv_26@yahoo.com
}

\begin{abstract}
Abstrak
Semangat Profesionalisme dalam Peribahasa Minagkabau. Semangat profesionalisme sangat penting dalam kehidupan manusia. Semangat profesionalisme itu dapat ditransfer menjadi bagian dari sikap, perilaku, tindakan dan kebiasaan seseorang dalam melakukan sesuatu. Nilai-nilai yang mendorong munculnya semangat profesionalisme dalam bentuk sikap, perilaku, dan tindakan profesional diperkirakan tersimpan juga dalam peribahasa setiap etnik di Indonesia termasuk peribahasa Minangkabau. Terkait dengan itu, tulisan ini merupakan suatu upaya untuk mencermati dan membicarakan semangat profesionalisme yang terkandung dalam peribahasa Minangkabau. Kajian dilakukan dari perspektif bagaimana bahasa mencerminkan sikap dan perilaku penuturnya. Data untuk kajian ini diambilkan dari sumber-sumber tertulis berupa kumpulan peribahasa yang telah didokumentasikan dan peribahasa-peribahasa yang digunakan dalam pertuturan sehari-hari masyarakat Minangkabau. Hasil kajian ini menunjukkan bahwa peribahasa Minangkabau mengandung nilai-nilai yang dapat mendorong masyarakat Minangkabau untuk memelihara tindakan, kebiasaan, perilaku dan sikap profesional dalam kehidupan sehari-harinya.
\end{abstract}

Kata kunci: Profesionalisme, profesional, nilai, dan peribahasa.

\begin{abstract}
The spirit of professionalism in Minangkabau Proverbs. The spirit of professionalism is very essential in human life. The spirit of professionalism then can be transferred into someone's attitude, behavior, action and habit in doing something It is assumed that the values triggering the spirit of professionalism in the form of professional attitude, behavior, and action can be found in the proverbs of every ethnics in Indonesia including Minangkabau proverbs. Thus, this writing is an attempt to observe and discuss the spirit of professionalism in Minangkabau proverbs. The study is done from the perspective of how language reflects the attitude and behavior of its speakers. The data for this study is collected from written documents of Minangkabau proverbs and the proverbs used in daily communication. The result of the study indicates that Minangkabau proverbs contains the values that can trigger Minangkabau people to keep their professional attitude, behavior, habit, and action in their daily life.
\end{abstract}

Keywords : Professionalism, professional, values, and proverbs. 


\section{PENDAHULUAN}

Suatu pekerjaan akan berhasil dengan baik jika dikerjakan secara profesional. Seseorang akan disegani dan diapresiasi dengan baik dalam suatu unit atau institusi jika ia bekerja secara profesional. Suatu institusi akan memiliki suatu suasana yang kondusif dalam menjalankan tugas dan tanggung jawabnya dan semua komponen bergerak dan berfungsi secara spontan, jika pola-pola manajemen dijalankan secara profesional. Jika sebuah instansi atau sebuah perusahaan berencana menambah atau merekrut pegawai atau karyawan, instansi atau perusahaan itu akan lebih memilih atau merekrut tenaga-tenaga profesional. Hasil dari suatu pekerjaan akan buruk dan tidak berkualitas jika pekerjaannya tidak dilakukan secara profesional. Sebuah unit usaha akan ambruk seketika jika tidak dikelola secara profesional. Ilustrasi-ilustrasi di atas memperlihatkan kepada kita bahwa menjadi profesional dalam setiap tindakan sangat penting dalam berbagai aspek kehidupan.

Bila kita runut dan baca serta renungkan lebih dalam, kemajuan suatu bangsa dan ketinggian peradabannya, ternyata tergantung kepada sejauh mana sikap dan tanggung jawab profesionalisme masing-masing anak bangsa itu ada pada dirinya dan diimplementasikan ke dalam setiap profesi yang diembannya. Negaranegara maju dan yang dianggap sudah maju memiliki sebutan profesional untuk setiap profesi. Ada dosen dan guru serta pendidik profesional. Ada pesepak bola profesional. Ada petani profesional. Ada petinju profesional. Ada pebisnis profesional. Sebutan profesional dapat melekat kepada semua pekerjaan yang digeluti.

Mengingat begitu pentingnya menjadi seseorang yang profesional dalam berbagai aspek kehidupan, tulisan ini mencoba secara ringkas dan pendek saja membicarakan beberapa hal terkait dengan semangat profesionalisme yang pada akhirnya dapat diwujudkan menjadi sikap, perilaku, dan kebiasaan dalam berbagai aspek kehidupan. Adapun hal-hal yang akan dibicarakan pada tulisan ini adalah (1) apakah yang dimaksud dengan profesional dan profesionalisme?; (2) adakah semangat profesionalisme dalam peribahasa Minangkabau?; (3) manakah peribahasa Minangkabau yang mengandung semangat profesionalisme?

\section{PROFESIONAL DAN \\ PROFESIONALISME}

Dalam kamus Besar Bahasa Indonesia edisi kedua cetakan keempat tahun 1995 halaman 789, kata profesional sebagai ajektiva memiliki tiga penjelasan yaitu (1) bersangkutan dengan profesi; (2) memerlukan kepandaian khusus untuk menjalankannya; (3) mengharuskan adanya pembayaran untuk melakukannya. Terkait dengan penjelasan di atas, jika seseorang berprofesi sebagai guru atau dosen, pebisnis, pesepak bola, petinju, dan petani, ia harus memiliki kepandaian khusus untuk menjalankan tugasnya sesuai dengan profesi masing-masingnya. Ia akan mendapat imbalan atau bayaran dari profesinya itu.

Masih dalam kamus yang sama, edisi dan cetakan yang sama, profesionalisme sebagai kata benda berkaitan dengan mutu, kualitas, dan tindak tanduk yang merupakan ciri suatu profesi atau orang yang profesional. Merujuk kepada pengertian tersebut, guru atau dosen profesional adalah guru atau dosen yang bermutu, berkualitas dan bertindak-tanduk sebagai seorang guru atau dosen. Pebisnis profesional adalah pebisnis yang bemutu dan berkualitas. Petinju profesional adalah petinju yang 
bermutu dan berkualitas. Petani profesional adalah petani yang bermutu dan berkualitas. Intinya adalah bahwa seseorang yang dianggap profesional adalah seseorang yang dapat menghasilkan suatu pekerjaan yang bermutu, berkualitas dan tepat waktu yang dimungkinkan terjadi bersebab dari pengetahuan dan keterampilan yang dimilikinya baik yang didapatkan melalui pendidikan formal, pengalaman hidup sehari-hari dan sumber-sumber lainnya yang mungkin memberikan pengetahuan dan keterampilan kepadanya.

\section{BAHASA DAN PENUTURNYA}

Dalam kehidupan manusia, bahasa
tidak hanya berfungsi sebagai alat komunikasi. Lebih dari itu, bahasa oleh Chaika (1989) disebut sebagai cerminan berbagai aspek sosial penuturnya (The social mirror of the speaker). Sementara itu Duranti (1997) dan Foley (1997) mengemukakan hubungan yang begitu erat antara bahasa dan kebudayaan. Bahasa adalah cerminan budaya masyarakat penuturnya. Sebaliknya, budaya masyarakat penutur suatu bahasa dapat dibaca melalui bahasanya. Di samping itu, bahasa bagi penuturnya juga dapat digunakan sebagai pencitraan dan pembentuk realitas. Bahkan lebih dari itu, bahasa digunakan untuk membentuk hiperrealitas. Kiranya tidaklah terlalu berlebihan bila kita sebut atau munculkan suatu pernyataan, language is for all. Bahasa adalah untuk siapa saja dan untuk apa saja.

Terkait dengan kutipan-kutipan pendapat sebagaimana dikemukakan di atas, bahasa Minangkabau sebagai salah satu bahasa daerah di Indonesia tidak hanya berfungsi sebagai alat komunikasi tetapi juga menyimpan nilai-nilai yang menjadi panduan dan pedoman hidup penuturnya. Ini diperkuat oleh pendapat yang dikemukan oleh Jacob Sumardjo (2003) yang juga telah dikutip pada dua tulisan sebelumnya oleh Oktavianus (2005 dan 2009) sebagai dasar berpijak untuk melihat filsafat etnik di Indonesia. Kutipan pendapat tersebut adalah sebagai berikut.

Filsafat orang Indonesia ada di balik pepatah-petitih, di balik rumah-rumah adat, di balik upacara-upacara adat, di balik mitos-mitos tua, di balik ragam hias pakaian yang mereka kenakan, di balik bentuk-bentuk tarian mereka, di balik musikmusik yang mereka mainkan, di balik persenjataan, di balik sistem pengaturan sosialnya dan lain-lain (Jacob Sumarjo, 2003).

\section{PERIBAHASA MINANGKABAU}

Kita tentu saja dapat menghubungan pernyataan Jacob Sumarjo di atas dengan menyebutkan bahwa filsafat orang Minangkabau tentu ada pula di balik ribuan peribahasanya. Peribahasa-peribahasa itu sebagiannya telah dihimpun ke dalam bentuk dokumen tertulis oleh oleh Hakimy, 2001, 1996; Nafis, 1996, Pamuncak K. St, N. St. Iskandar, dan A Dt. Madjoindo (Edisi ke-11 Tahun 2000), Saleh, dkk (1999), Fanany (2003). Tulisan-tulisan ini berisi kumpulan peribahasa yang memuat deskripsi ringkas tentang maksud peribahasa tersebut. A.B Datuak Madjo Indo (1999) menulis buku yang berjudul Kato Pusako. Buku tersebut berisi uraian tentang hakikat orang Minangkabau, cara bersikap dan berperilaku serta bertindak dalam berbagai aspek kehidupannya. Amir (1997) telah pula menulis buku berjudul Adat Minangkabau: Pola dan Tujuan Hidup Orang Minang. Tulisan-tulisan di atas telah memberikan gembaran tentang nilai-nilai yang seharusnya menjadi pedoman tidak saja bagi 
orang Minang tetapi juga bagi etnis lainnya di luar Minangkabau.

Kajian dalam bentuk penelitian dilakukan oleh Oktavianus (2005, 2006, dan 2007); Oktavianus dan Lindawati (2008) dan Oktavianus, dkk (2011) pada Pusat Studi dan Informasi Kebudayaan Minangkabau. Tulisan-tulisan dalam bentuk artikel pendek yang disajikan dalam seminar juga dilakukan oleh Oktavianus (2010) dan Oktavianus (2012). Ada dua hal penting yang dapat disimpulkan dari kajian dan tulisan tersebut di atas. Pertama, rekonstruksi terhadap peribahasa Minangkabau memperlihatkan bahwa peribahasa tersebut memiliki nilai-nilai yang terkonfigurasi secara kompleks (Oktavianus dan Lindawati, 2008). Kedua, sebuah peribahasa dapat mengandung nilai dan makna yang tidak terbatas Nilai-nilai tersebut merupakan cikal-bakal sikap, perilaku positif termasuk semangat profesionalisme yang seharusnya dimiliki oleh setiap orang dalam mengemban profesinya sebagaimana yang akan dibahasa pada tulisan ini.

\section{SEMANGAT \\ DALAM MINANGKABAU \\ PROFESIOALISME PERIBAHASA}

Ada nilai-nilai dalam peribahasa Minangkabau yang dapat dipedomani seseorang bahwa dalam melakukan pekerjaan ia harus memiliki pengetahuan dan keterampilan jika ingin disebut profesional. Bentuk-bentuk peribahasa tersebut adalah sebagai berikut.

1. Elok rumah karano tukang, rusak rumah karano tukang 'baik rumah karena tukang, rusak rumah karena tukang'

\section{Kapalang tukang binaso kayu, kapalang malin rusak kaji 'kepalang tukang binasa kayu, kepalang malin rusak kaji'}

Peribahasa (1) menggambarkan bahwa baik buruknya rumah tergantung kepada tukang. Rumah akan menjadi baik jika tukangnya memiliki pengetahuan dan keterampilan tentang cara-cara membuat rumah. Rumah akan menjadi rusak dan tidak berkualitas jika tukangnya tidak memiliki pengetahuan dan keahlian serta keterampilan tentang itu. Hal yang sama juga diungkapkan pada peribahasa (2) Tukang yang kepalang tukang atau kurang memiliki keterampilan atau keahlian sebagai tukang akan menyebabkan kayu menjadi rusak atau binasa. Salah potong, salah ukur, dan salah pasang adalah kemungkinan-kemungkinan yang bisa terjadi. Hasil pekerjaannya tidak bermutu dan tidak berkualitas. Seorang malin yang kepalang malin dapat merusak kaji.

Peribahasa (1) dan (2) di atas diungkapkan secara metaforis dan dapat diumpamakan ke pekerjaan-pekerjaan atau profesi lainnya. Tukang dapat merupakan representasi dari profesi lainnya seperti guru, pebisnis atau pedagang, petani, pesepak bola, petinju, penyanyi dan lainlainnya. Profesi-profesi ini jika tidak digeluti dengan suatu keahlian akan mendatangkan kerugian. Guru bisa membuat murid menjadi bingung. Petani, pebisnis atau pedagang bisa jadi rugi berkepanjangan sementara ia sudah mengeluarkan modal untuk itu. Pemain bola, petinju dan penyanyi bisa jadi kalah saja di setiap kompetisi. Di Minangkabau, sesuatu yang dilakukan dengan tidak profesional disindir dengan peribahasa berikut.

2. Minyak abih, samba tak lamak 'minyak habis, sambal tidak enak' 


\section{Arang abih, basi binaso}

'arang habis, besi binasa'

4. Utang tabayia, lansai indak 'hutang terbayar, tetapi tidak lunas.

Peribahasa (2), (3), (4) di atas menggambarkan suatu keadaan di mana suatu pekerjaan sudah dilakukan tetapi hasilnya tidak maksimal atau tidak berkualitas bersebab dari kurangnya keahlian dan keterempilan pelakunya. Dalam memberikan nasihat atau peringatan kepada seseorang di Minangkabau, konstruksi sintaksis peribahasa di atas dapat muncul sebagai berikut.

5. Jan sampai minyak abih, samba tak lamak 'jangan sampai (terjadi) minyak habis, sambal tidak enak'

6. Jan sampai arang abih, basi binaso

'jangan sampai (terjadi) arang habis, besi binasa'

7. Jan sampai utang tabayia, lansai indak

'jangan sampai (terjadi) hutang terbayar, tetapi tidak lunas.

Untuk menjadi profesional dalam suatu pekerjaan, pengetahuan dan keterampilan yang dibutuhkan untuk pekerjaan itu harus benar-benar dikuasai. Peribahasa Minangkabau menggambarkannya sebagai berikut.
8. Lubuak aka, lautan (tapian) budi

'lubuk akal, lautan (tepian) budi'

(Usman, 2002:379)

Dari peribahasa (5) di atas, seseorang yang profesional di bidangnya memiliki pengetahuan yang dalam dan budi pekerti yang tinggi. Jadi, ahli dan terampil saja dalam suatu bidang tidak cukup untuk menjadi profesional. Budi pekerti juga sangat dipentingkan. Kecerdasan rasio harus dikombinasikan dengan kecerdasan raso.

Jika peribahasa di atas dipahami sebagai sebuah teks yang kontekstual di Minangkabau dan merujuk kepada apa yang dikemukakan oleh Jacob Sumarjo (2003) sebagaimana dikutip di atas, orang-orang profesional di bidangnya tentu saja harus lahir pula dari Ranah Minang. Mungkin filosofi berpikir demikian yang membuat orang Minang banyak sukses baik di kampung halamannya maupun di perantauan. Sampai hari ini, rumah makan Minang masih terkenal di mana-mana. Pengusaha dan profesional muda banyak juga yang berasal dari tanah Minang. Tentu saja ini tidak dimaksudkan untuk mengagung-agungkan Minangkabau.

Untuk menjadi profesional dalam suatu pekerjaan, memiliki pengetahuan dan keterampilan yang tinggi saja ternyata belumlah cukup. Untuk mewujudkan pengetahuan dan keterampilannya, ada halhal lain yang diperlukan. Ia akan menemui kesulitan dan hambatan. Ia harus mewaspadai setiap kemungkinan yang akan terjadi. Oleh sebab itu, profesional dalam bertindak, bersikap dan berperilaku adalah juga suatu keharusan sebagaimana digambarkan pada tabel berikut. 


\section{Tabel 1: Menjadi Profesional}

\begin{tabular}{|c|c|c|}
\hline Profesi & Yang harus dimiliki & Keperluannya \\
\hline \multirow{7}{*}{$\begin{array}{l}\text { Guru/dosen, } \\
\text { pebisnis/pedagang, } \\
\text { pesepak bola } \\
\text { profesional dan } \\
\text { profesi-profesi } \\
\text { lainnya }\end{array}$} & $\begin{array}{l}\text { Keahlian di bidangnya } \\
\text { Minyak abih samba tak lamak. Arang abih } \\
\text { basi binaso. Utang tabayia, lansai indak. } \\
\text { 'Minyak habis, sambal tidak enak. Arang } \\
\text { habis, besi binasa. Hutang terbayar, lunas } \\
\text { tidak'. }\end{array}$ & $\begin{array}{l}\text { Menghindari pekerjaan asal jadi } \\
\text { saja yang. Orang yang profesional } \\
\text { adalah orang hasil pekerjaannya } \\
\text { bermutu. }\end{array}$ \\
\hline & $\begin{array}{l}\text { Kesantunan } \\
\text { Muluik manih kucindan murah } \\
\text { 'mulut manis, kecindan murah' }\end{array}$ & $\begin{array}{l}\text { Disenangi oleh orang seke- } \\
\text { lilingnya sehingga profesinya } \\
\text { dapat dijalankan dengan baik. } \\
\text { Orang yang profesional adalah } \\
\text { orang yang santun. }\end{array}$ \\
\hline & $\begin{array}{l}\text { Kewaspadaan } \\
\text { Tau di rantiang ka mancucuak, } \\
\text { tau di dahan ka maimpok. } \\
\text { 'tau di ranting yang akan menusuk' } \\
\text { Tau di dahan yang akan menimpa' }\end{array}$ & $\begin{array}{l}\text { Menghindari hal-hal yang mungkin } \\
\text { mendatangkan ke-rugian atau } \\
\text { sesuatu yang tidak diingini. Orang } \\
\text { yang profesional adalah orang } \\
\text { yang selalu waspada. }\end{array}$ \\
\hline & $\begin{array}{l}\text { Kehati-hatian } \\
\text { Bajalan salangkah maadok suruik } \\
\text { Bakato sapatah dipikiri } \\
\text { 'berjalan selangkah, } \\
\text { melihat ke belakang, } \\
\text { 'berkata sepatah dipikirkan' }\end{array}$ & $\begin{array}{l}\text { Agar pekerjaan dapat dilaku-kan } \\
\text { dengan baik dan hasilnya bermutu } \\
\text { dan berkualitas. Orang yang } \\
\text { profesional adalah orang yang } \\
\text { selalu hati-hati. }\end{array}$ \\
\hline & $\begin{array}{l}\text { Solidaritas } \\
\text { Lamak di awak, katuju di urang } \\
\text { 'enak bagi kita disukai oleh orang lain' }\end{array}$ & $\begin{array}{l}\text { Menghadapi hal-hal yang } \\
\text { menyulitkan dalam meng-emban } \\
\text { profesi. Orang profesional adalah } \\
\text { orang yang memiliki rasa } \\
\text { solidaritas. }\end{array}$ \\
\hline & $\begin{array}{l}\text { Proporsional } \\
\text { Babuek baiak pado-padoi, } \\
\text { Babuek buruak sakali jangan' } \\
\text { 'berbuat baik pada-padai' } \\
\text { berbuat buruk sekali jangan' }\end{array}$ & \multirow[t]{2}{*}{$\begin{array}{l}\text { Menjaga keselamatan kerja dan } \\
\text { secara tidak langsung berujung } \\
\text { kepada mutu dan kualitas. Orang } \\
\text { yang profesional adalah orang } \\
\text { melakukan sesuatu } \\
\text { proporsional secara }\end{array}$} \\
\hline & $\begin{array}{l}\text { Malabihi ancak-ancak, } \\
\text { Mangurangi sio-sio } \\
\text { 'jangan melebihi atau mengurangi } \\
\text { dari yang semestinya' }\end{array}$ & \\
\hline
\end{tabular}




\begin{tabular}{|c|c|c|}
\hline \multirow{13}{*}{$\begin{array}{l}\text { Guru/dosen, } \\
\text { pebisnis/pedagang, } \\
\text { pesepak bola } \\
\text { profesional dan } \\
\text { profesi-profesi } \\
\text { lainnya }\end{array}$} & $\begin{array}{l}\text { Berwawasan dan inovatif } \\
\text { Duduak marawik ranjau, } \\
\text { Tagak maninjau jarak } \\
\text { 'duduk meraut ranjau, } \\
\text { Tegak meninjau jarak. }\end{array}$ & $\begin{array}{l}\text { Selalu menggunakan waktu dan } \\
\text { memberdayakan pikiran dalam } \\
\text { upaya mengembangkan profesi. } \\
\text { Orang yang profesional adalah } \\
\text { orang yang memiliki wawasan dan } \\
\text { inovatif }\end{array}$ \\
\hline & Adaptatif & \multirow[b]{2}{*}{\begin{tabular}{l} 
Memperhatikan \\
\multicolumn{2}{r}{ norma-norma } \\
setempat dalam menjalankan \\
profesi sehingga \\
menimbulkan konflik didak \\
perbenturan nilai. Orang yang \\
profesional adalah orang yang \\
mampu beradaptasi di manapun ia \\
berada.
\end{tabular}} \\
\hline & $\begin{array}{l}\text { Di ma bumi dipijak, } \\
\text { di situ langik dijujuang, } \\
\text { di situ rantiang dipatah, } \\
\text { di situ aia disauak. } \\
\text { 'di mana bumi dipijak, } \\
\text { di situ langit dijunjung, } \\
\text { di situ ranting dipatah, } \\
\text { di situ air disauk' }\end{array}$ & \\
\hline & Dinamis & \multirow{2}{*}{$\begin{array}{l}\text { Menghadapi keberagaman dalam } \\
\text { menjalankan suatu profesi. Orang } \\
\text { yang profesional adalah orang } \\
\text { yang dinamis. }\end{array}$} \\
\hline & $\begin{array}{l}\text { Tagang bajelo-jelo, } \\
\text { kandua badantiang-dantiang } \\
\text { 'tegang berjela-jela, } \\
\text { Kendor berdenting-denting' }\end{array}$ & \\
\hline & Bijaksana & \multirow[b]{2}{*}{$\begin{array}{l}\text { Mengatasi berbagai kesulitan } \\
\text { dalam menjalankan tugas dengan } \\
\text { tidak merugikan pihak manapun } \\
\text { dan profesi dapat dijalankan } \\
\text { dengan baik. Orang yang } \\
\text { profesional adalah orang yang } \\
\text { bijaksana. }\end{array}$} \\
\hline & $\begin{array}{l}\text { Bak mancabuik banang dalam ta-puang, } \\
\text { banang indak putuih, tapuang indak } \\
\text { taserak. } \\
\text { 'bak mencabut benang dari dalam tepung. } \\
\text { Benang tidak putus, tepung tidak tumpah' }\end{array}$ & \\
\hline & Adil & \multirow{6}{*}{$\begin{array}{l}\text { Menjaga objektivitas dalam } \\
\text { menjalankan profesi. Orang yang } \\
\text { profesional adalah orang yang } \\
\text { mampu bersikap adil. }\end{array}$} \\
\hline & $\begin{array}{l}\text { Tibo di mato indak dipiciangkan, } \\
\text { Tibo di paruik indak dikampihan } \\
\text { 'tiba di mata tidak dipicingkan, } \\
\text { Tiba di perut tidak dikempiskan' }\end{array}$ & \\
\hline & Bertanggung jawab & \\
\hline & $\begin{array}{l}\text { Tangan mencencang, } \\
\text { Bau mamikua } \\
\text { 'tangan mencencang, } \\
\text { Bahu memikul' }\end{array}$ & \\
\hline & Rendah hati & \\
\hline & $\begin{array}{l}\text { Mandi di ilia-ilia, } \\
\text { bakato di bawah-bawah } \\
\text { 'mandi di hilir-hilir, } \\
\text { berkata di bawah-bawah' }\end{array}$ & \\
\hline
\end{tabular}




\begin{tabular}{|l|l|l|}
\hline & \multirow{2}{*}{ Teguh pendirian } & \\
\cline { 2 - 3 } & $\begin{array}{l}\text { Indak kuniang dek kunik } \\
\text { 'tidak kuning karena kunit' } \\
\text { Indak itam karano arang } \\
\text { 'tidak hitam karena arang' }\end{array}$ & \\
\hline
\end{tabular}

Para penulis, peneliti dan pakar lainnya menelaah makna dan nilai yang terkandung dalam ungkapan berikut ini dari sudut pandang yang berbeda-beda. Bila dicermati secara lebih mendalam, semangat profesionalisme dalam peribahasa dan ungkapan Minangkabau dapat pula dicermati pada ungkapan berikut.

\begin{tabular}{|c|c|c|}
\hline 9. & $\begin{array}{l}\text { Nan buto pahambuih lasuang } \\
\text { Nan pakak palapeh badia } \\
\text { Nan patah pangajuik ayam } \\
\text { Nan lumpuah paunyi rumah } \\
\text { Nan bodoh/binguan ka disuruah-suruah } \\
\text { Nan pandai tampek batanyo } \\
\text { Nan cadiak bakeh baiyo } \\
\text { Nan kayo tampek batenggang } \\
\text { Nan rancak pananti tamu } \\
\text { (Hakimy, 2001:13-14). }\end{array}$ & $\begin{array}{l}\text { Yang buta penghembus lesung } \\
\text { Yang tuli pemasang bedil } \\
\text { Yang patah pengejut ayam } \\
\text { Yang lumpuh penghuni rumah } \\
\text { Yang bodoh di suruh-suruh } \\
\text { Yang pandai tempat bertanya } \\
\text { Yang cerdik tempat beriya } \\
\text { Yang kaya tempat meminjam } \\
\text { Yang rancak untuk menanti tamu }\end{array}$ \\
\hline
\end{tabular}

Ungkapan di atas mencerminkan adanya elemen-elemen nilai yang berujung pada lahirnya sikap dan perilaku profesional di Minangkabau. Dalam ungkapan di atas, yang buta, yang pekak/tuli, yang patah, yang lumpuh, yang bodoh, yang pandai, yang cerdik, yang kaya, yang rancak 'cantik/gagah', harus dimanfaatkan sesuai dengan kapasitasnya masing-masing. Penempatan seseorang sesuai dengan kapasitas dirinya sebagaimana tercermin dari ungkapan di atas adalah agar dia mampu melakukan pekerjaan yang dibebankan kepadanya dengan baik. Bertanya tentu saja harus kepada orang pandai bukan kepada orang bodoh agar mendapatkan jawaban yang memuaskan. Batenggang 'meminjam jika seseorang kesulitan (uang)' tentu harus kepada orang kaya. Penanti tamu haruslah orang yang rancak 'cantik/gagah'. Tidak mungkin pula orang buta yang digunakan sebagai penanti tamu. Jika dimungkinkan, tentu saja ada sesuatu yang kurang.

\section{SIMPULAN}

Dari uraian di atas, kita dapat menyimpulkan dua hal. Pertama, peribahasa Minangkabau mengandung nilai-nilai yang mendorong munculnya semangat profesionalisme. Semangat profesionalisme tersebut diwujudkan ke dalam berbagai bentuk peribahasa. Kedua, dari pencermatan terhadap nilai-nilai yang terkandung dalam peribahasa Minangkabau, seseorang yang profesional dalam melakukan profesinya adalah orang yang ahli di bidangnya, santun, 
waspada, hati-hati/cermat, berjiwa solidaritas, proporsional, inovatif, mudah beradaptasi, dinamis, bijaksana, adil, bertanggung jawab, rendah hati, teguh pendirian, dan mampu memberdayakan segala sesuatu sesuai dengan kapasitasnya. Dengan demikian, seseorang dapat dikatakan profesional apabila ia mampu mengkombinasikan antara hard skills dan soft skills dalam dirinya dalam mengamban suatu pekerjaan atau profesi.

\section{UCAPAN TERIMA KASIH}

Perkembangan ilmu pengetahuan tidaklah berdiri sendiri. Suatu ide atau gagasan yang telah muncul sebelumnya akan mendorong dan memicu timbulnya ide atau gagasan berikutnya. Oleh sebab itu, pada kesempatan ini dan pada bagian akhir tulisan ini, izinkanlah penulis menyampaikan ucapan terima kasih dan memberikan apresiasi yang tinggi kepada para penulis dan pakar baik yang terkait dengan konsep dan teori bagaimana bahasa berhubungan erat dengan penuturnya maupun para pengumpul dan penulis peribahasa Minangkabau yang dikutip dan digunakan dalam tulisan ini sebagaimana yang sudah disebutkan pada pustaka rujukan. Ucapan terima kasih dan apresiasi juga disampaikan kepada Mitra Bestari Jurnal Bahasa dan Sastra yang telah menelaah tulisan ini dan Dewan Redaksi yang telah memberikan fasilitas bagi penerbitan artikel ini. Semoga semua jerih payah pihak-pihak yang berkontribusi dalam tulisan ini menjadi amal saleh hendaknya.

\section{PUSTAKA RUJUKAN}

Amir.1997. Adat Minangkabau: Pola dan Tujuan Hidup Orang Minang. Jakarta: PT. Mutiara Sumber Widya.

Chaika, E. 1989. Language: The Social Mirror. New York: Newbury House Publishers.

Duranti, A.1997. Linguistic Anthropology. First published, Cambridge: Cambrid-ge University Press.

Fanany, I, dan Fanany, R.2003. Wisdom of the Malay Proverbs. Kuala Lumpur : Dewan Bahasa dan Pustaka.

Foley, W. A.1997. Antrophological Linguistics: An Introduction. Blackwell.

Hakimy, I,R,P.2001. Rangkaian Mustika Adat Basandi Syarak di Minangkabau. Bandung. PT. Remaja Rosda Karya. .1996. 1000 Pepatah-PetitihMamang-Bidal-Pantun-Gurindam. Bandung : Remaja Karya.

Indo, A.B.M.1999. Kato Pusako: Pepatah, Petitih, Mamang, Pantun, Ajaran dan Filsafat Minangkabau. Jakarta : PT. Rora Karya.

Nafis, A. 1996. Peribahasa Minangkabau. Jakarta: PT. Intermasa.

Oktavianus. 2005. "Kias dalam Bahasa Minangkabau". Disertasi Doktor. Bali: Pascasarjana Universitas Udayana. .2006. Analisis Wacana Lintas Bahasa. Padang: Andalas University Press.

.2007. "Cerminan Nilai Budaya Lintas Budaya”. Jurnal LOGAT. Fakultas Sastra Universitas Sumatera Utara. 
$.2009 a$.

"Peribahasa, Kekuasaan, dan Globalisasi". Makalah pada Seminar Nasional di Medan.

.2009b. Peranan Adat dan Budaya dalam Penyelenggaraan Pemerintahan. Makalah disampaikan pada Pencerahan dan Pembekalan tentang Etika Pemerintahan dalam Mewujudkan "Good Local Governance" di Solok 30 Maret 2009. 2010 .

"Nilai-Nilai

Kewirausahaan dalam Peribahasa Minangkabau". Makalah Seminar Internasional di Pascasarjana Universitas Andalas. .2011. Revitalisasi Nilai-Nilai

Dalam Pepatah Petitih Minangkabau sebagai Pengembangan Jati Diri dan Karakter Bangsa. Penelitian Pusat Studi dan Informasi Kebudayaan Minangkabau (PSIKM)

.2012. Antikorupsi dalam

Peribahasa Minangkabau. Makalah

Seminar Internasional di

Universitas Negeri Padang, 20-21

Oktober 2012.

Oktavianus dan Lindawati. 2008. Rekonstruksi Nilai Budaya dari Peribahasa Minangkabau dan Pembudidayaannya dalam Upaya Memperkokoh Filosofi Adat Basandi Syarak-Syarak Basandi Kitabullah. Jurnal Lingua Didaktika Universitas Negeri Padang.

Pamuntjak, K. St., N. St. Iskandar dan A Dt. Madjoindo.2000. Peribahasa; Edisi ke-11. Jakarta: Balai Pustaka

Saleh, Abd, dkk. 1999. Ungkapan Minangkabau. Padang: Laporan Penelitian oleh Lembaga Kerapatan Adat Alam Minangkabau.
Sumardjo, J. 2003. Filsafat Etnik Indonesia. Pikiran Rakyat 18 Januari, halaman 3 kol 3-4.

Tim Penyusun Kamus Pusat Pembinaan dan Pengembangan Bahasa.1995. Kamus Besar Bahasa Indonesia (KBBI). Jakarta : Balai Pustaka. 